Leipzig, Leipzig, Germany; ${ }^{2}$ LIFE-Leipzig Research Center for Civilisation Diseases, University of Leipzig, Leipzig, Germany; ${ }^{3}$ Institute of Social Medicine, Occupational Health and Public Health, University of Leipzig, Leipzig, Germany

Background/Aims Subjects with Mild Cognitive Impairment (MCI) constitute a risk population of developing dementia and thus a population of clinical interest. This study reviews recent work on the incidence of $\mathrm{MCI}$ in the elderly.

Methods Incidence papers were identified by a systematic literature search. Studies on incidence of MCI were considered if they identified 'cognitively mild impaired' subjects by application of the MCI criteria, used the 'person-years-at-risk' method, and were based on population-based or community-based samples.

Results Nine studies were identified. Incidence of Amnestic MCI subtypes ranged between 9.9 and 40.6 per 1000 person-years, and incidence of Non-amnestic MCI subtypes was found to be 28 and 36.3 per 1000 person-years. Regarding any $M C I$, incidence rates of 51 and 76.8 per 1000 person-years have been found. A higher risk of incident MCI mainly was found for higher age, lower education and hypertension.

Discussion Incidence rates of MCI varied widely, and possible risk factors for incident MCI were analysed only to a limited extent. Findings call for an agreement concerning the criteria used for $\mathrm{MCI}$ and the operationalisation of these criteria.

Declaration of Interest This review was published with affiliation of the Leipzig Research Center for Civilisation Diseases (LIFE, Universität Leipzig). LIFE is financed by means of the European Union, by the European Regional Development Fund (ERDF) and by means of the Free State of Saxony within the framework of the excellence initiative.

\section{P1-226 THE POSSIBILITY OF ADVENTURE IS NOT EXCLUDED: THE CAREER OF INTERNATIONAL EPIDEMIOLOGIST MELVILLE DOUGLAS MACKENZIE (1889-1972)}

doi:10.1136/jech.2011.142976e.19

D Macfadyen. ${ }^{*}$ Royal College of Physicians of Edinburgh, UK

Introduction The International Health Conference convened in New York in 1946 recorded its appreciation to Mackenzie. He chaired the Drafting Committee and signed the final act to establish the WHO, on authority granted by the British Foreign Minister. Mackenzie arrived at this position after a range of international health work that was unmatched.

Method The paper draws on family papers, Mackenzie's publications, League of Nations' Health Organization Archives, Sprigings recent biographic essay Feed the people and prevent disease, and be damned to their politics, ${ }^{1}$ and Haswell's unpublished biography, The Man Who Stopped a War.

Results In 1922/1923, Mackenzie served in Russia with Nansen in the world's first large-scale multinational humanitarian intervention. He encountered not only famine, but cholera and epidemics of typhus and malaria of unprecedented scale. In 1928, now with the League of Nations' Health Organization, he helped to control a dengue epidemic that was paralysing economic life in Greece. Mackenzie's successes in epidemic control permitted him to nudge the Organization towards wider health engagement with several European countries, including England, Ireland and Scotland, and to dramatic assignments in Bolivia, Liberia and China.

Conclusions The scope and working methods of today's international health institutions evolved from the epidemiological work of pioneers in the League of Nations' Health Organization from Australia, Denmark, France, Germany, Italy, Poland, Switzerland, the UK, the USA and other countries. Those seeking to reform practices in humanitarian relief or in global health would benefit from studying this historical background.

\section{REFERENCE}

1. Sprigings Z, Mackenzie M. (1889-1972) 'Feed the people and prevent disease, and be damned to their politics'. In: Borowy I, Hardy A, eds. Biographies and Ideas in European Social Medicine between the World Wars: Peter Lang, 2008:103-23.

\section{P1-227 FACTORS ASSOCIATED WITH RENAL TRANSPLANTATION AND MORTALITY IN PATIENTS WITH TERMINAL CHRONIC RENAL DISEASE IN BRAZIL, 2000-2003}

doi:10.1136/jech.2011.142976e.20

E Machado, ${ }^{*}$ W Caiaffa, C C César, I Gomes, E Andrade, F Acúrcio, M Cherchiglia. Federal University of Minas Gerais, Belo Horizonte, Brazil

Background Inequalities have been reported in access to kidney transplantation in relation to demographic, socioeconomic, clinical and geographical. Patients waiting for kidney transplant face a number of competitive outcomes

Objective To investigate factors associated with access to kidney transplantation, considering the type of donor and death as competitive events.

Design and Source of Data observational, prospective non-concurrent, from the National Data Base on renal replacement therapies in Brazil. Relationship was conducted from deterministic-probabilistic System Authorisation Procedures of High Complexity/Cost, Hospital Information System and Information System on Mortality. Participants 17084 adult patients starting renal replacement therapy in Brazil from 01/01/2000 to 31/01/2000.

Variables Impact of individual variables (age, gender, region of residence, primary renal disease, hospitalisations) in the context of the dialysis unit (level of complexity, legal, HD machines and location) and the city (geographical region, location and Human Development Index-HDI) in likelihood of transplantation and death.

Results younger patients without diabetes, no history of hospitalisation, in dialysis treatment unit located in the state capital, living in the countryside, in cities with high HDI were more likely to transplant. Sex and level of complexity has only been associated with a living donor transplant. The results indicate differences in access to kidney transplantation, however, regarding gender, age 45 years and diabetes were lower inequality cadaver donor for transplantation. Older patients with diabetes, with hospitalisation, being treated in dialysis units are less complex, located in state capitals and municipalities with low HDI had a higher risk of death.

\section{P1-228 DECREASED BONE MASS IN WOMEN: IMPORTANCE OF EARLY DIAGNOSIS FOR HEALTHY AGEING}

doi:10.1136/jech.2011.142976e.21

${ }^{1} \mathrm{R} M$ da Silva, ${ }^{1} \mathrm{M}$ V de L Saintrain, ${ }^{1} \mathrm{Z}$ V Bruno, ${ }^{1} \mathrm{~A}$ P G F Vieira, ${ }^{1} \mathrm{~S}$ V Saintrain. ${ }^{1}$ Universidade de Fortaleza, Fortaleza, Ceará, Brazil; ' Universidade Federal do Ceará, Fortaleza, Ceará, Brazil

Objectives Presuming that osteoporosis begins in middle aged women, the present study had as an objective to identify the prevalence of osteopenia and osteoporosis in women whose ages vary from 45 to 59 and from 60 or more.

Methodology The study analysed data from a gynaecologic outpatient clinic, related to patients files from 2000 to 2006. The following variables were analysed: age, the first and the last appointment's dates, the result of the bones mineral's density (DMO) classified by the categories: normal, osteopenia and osteoporosis. $\chi^{2}$ Test was used to verify associations between variables, considering $\mathrm{p}<0.05$.

Results Osteopororis was more frequent in the older age group (42.5\% vs $5.6 \%, \mathrm{p}<0.05)$, although osteopenia was more frequent in the younger group $(55.0 \%$ vs $47.1 \%, \mathrm{p}<0.05)$. 